\title{
Correlation and Evaluation of the Preoperative Computed Tomography with Preoperative Surgical Findings in Patients with Unsafe Chronic Supppurative Otitis Media
}

\author{
Navin Shukla ${ }^{1}$, Varuni Sharma ${ }^{2}$, Rakesh Kumar Giri ${ }^{1}$ \\ ${ }^{1}$ Department of Otorhinolaryngology at Shridev Suman Subharti Medical College, Dehradun. ${ }^{2}$ Department of Obstetrics and Gynaecology at Shridev Suman \\ Subharti Medical College, Dehradun
}

\begin{abstract}
Background: Chronic Suppurative Otitis Media (CSOM) is one of the most common causes of preventable hearing loss especially in developing countries. It is described as a condition of the middle ear that is characterized by persistent or recurrent discharge for three months or more through a perforation of the tympanic membrane. The aim and objective of the study is to correlate and compare preoperated computed tomography with preoperative surgical findings with unsafe chronic suppurative otitis media. Subjects and Methods: A prospective, analytical study was conducted among 90 patients with complaint of unsafe chronic suppurative otitis media which were randomly selected from outpatient Department of ENT at Shridev Suman Subharti Medical College, Dehradun, Uttarakhand. The patients comprised of both males as well as females and also of different age groups. Results: Among 90 study subjects, 32 (35.55\%) cases had conductive hearing loss, 11(12.22\%) cases had sensorineural type, 40(44.44\%) had mixed type and 7(7.77\%) had no response. On comparing the per operative findings with those of computed tomography, soft tissue mass in middle ear and mastoid was seen in 87 cases (96.66\%) per operatively whereas on computed tomography, it was observed in 80 cases $(88.88 \%)$. Mastoid air cells were found sclerosed in 72 cases (80\%) both per operatively and on computed tomography. Conclusion: In conclusion, the present study pointed that high resolution computed tomography scanning is a modality which can accurately image the pathological anatomy in unsafe chronic suppurative otitis media and represents a major advance in the diagnostic imaging of this disease.
\end{abstract}

Keywords: Unsafe chronic suppurative otitis media (CSOM), computed tomography, Uttarakhand.

Corresponding Author: Dr. Varuni Sharma, Department of Obstetrics and Gynaecology at Shridev Suman Subharti Medical College, Dehradun.

Received: March 2019

Accepted: March 2019

\section{Introduction}

In the recent years, computed tomography $(\mathrm{CT})$ played a significant role in the ability to diagnose and in the detection of temporal bone disorders. In developing countries, Chronic Suppurative Otitis Media (CSOM) is one of the most common causes of preventable hearing loss. ${ }^{[1]}$ In other words, it is defined as a condition of the middle ear that is characterized by persistent or recurrent discharge for three months or more through a perforation of the tympanic membrane. The incidence of CSOM is rapidly increasing in the developing countries due to poor nutrition in diet, poor hygienic practices and lack of health educational trainings. As per report of World Health Organization (WHO), global burden of CSOM accounts for around 28,000 deaths and a disease burden of over 2 million DALYs (DisabilityAdjusted Life Year) and if suitable treatment was not provided at the right time it leads into serious problem like irreversible local destruction of middle ear structures resulting in complications such as labyrinthitis, facial nerve paralysis, lateral sinus thrombosis, mastoiditis, meningitis, and intracranial abscess. ${ }^{[2]}$
Recently, high resolution computed tomography (HRCT) scanning has evolved as the standard imaging technique for temporal bone, but its exact role in preoperative assessment of patients with Chronic otitis media atticoantral disease still remains controversial. Many experienced otology surgeons seldom use computed tomography scanning arguing that nature and extent of pathology becomes evident during surgical dissection3. Some otologists use it regularly aiming to evaluate the extension of disease, schedule the surgical technique to be adopted and identify potential risk of complications4. Others reserve its' utilization for cases in which there is suspicion of complication, recurrence or diagnostic doubt.

The aim of the study is to correlate and compare preoperated computed tomography with preoperative surgical findings with unsafe chronic suppurative otitis media.

\section{Subjects and Methods}

A prospective, analytical study was conducted among 90 patients with unsafe chronic suppurative otitis media which 


\section{Shukla et al; Preaperative Camputed Tamagraphy in Unsale Chranic Supppurative Otitis Media}

were randomly selected from outpatient Department of Otorhinolaryngology at Subharti Medical College, Dehradun, Uttarakhand. The patients comprised of both males as well as females and also of different age groups.

A detailed history with regard to otorrhoea, deafness, tinnitus, otalgia and vertigo was taken and recorded in a systemic manner. A complete general physical examination was carried out followed by otorhinolaryngological examination which included otoscopic examination and examination under microscope. Assessment of hearing was done by tuning fork tests and pure tone audiometry.

Routine haematological and urine investigations were carried out in each case along with X-ray chest PA view and ECG wherever indicated. Patients with malignancy of the ear, patients unfit for surgery or anesthesia and patients who were pregnant were excluded from the study5. Written informed consent were taken from study subjects and approval for the study was obtained from Institutional Research and Ethical Committee.

\section{Results}

A total number of 90 cases of unsafe type of chronic suppurative otitis media were selected for present study.

Table 1: Correlation between computed tomography and surgical findings

\begin{tabular}{|l|l|l|l|}
\hline & Feature & $\begin{array}{l}\text { Present } \\
\text { preoperatively }\end{array}$ & $\begin{array}{l}\text { On computed } \\
\text { tomography }\end{array}$ \\
\hline 1. & Soft tissue mass & $96.66 \%$ & $88.88 \%$ \\
\hline 2. & Aeration mastoid & $80 \%$ & $80 \%$ \\
\hline 3. & $\begin{array}{l}\text { Tegmen tympani } \\
\text { erosion }\end{array}$ & $31.11 \%$ & $18.88 \%$ \\
\hline 4. & Sinus plate erosion & $8.88 \%$ & $6.66 \%$ \\
\hline 5. & Facial N. dehiscence & $32.22 \%$ & $14.44 \%$ \\
\hline 6. & $\begin{array}{l}\text { Lat. Semi-circular } \\
\text { canal fistula }\end{array}$ & $15.55 \%$ & $13.33 \%$ \\
\hline 7. & Malleus erosion & $37.77 \%$ & $35.55 \%$ \\
\hline 8. & Incus erosion & $76.66 \%$ & $47.77 \%$ \\
\hline 9. & Stapes erosion & $40 \%$ & $18.88 \%$ \\
\hline 10. & Dis. Outside M. ear & $18.88 \%$ & $17.77 \%$ \\
\hline
\end{tabular}

As observed in the above table, on comparing the per operative findings with those of computed tomography, soft tissue mass in middle ear and mastoid was seen in 87 cases $(96.66 \%)$ per operatively whereas on computed tomography, it was observed in 80 cases $(88.88 \%)$. Mastoid air cells were found sclerosed in 72 cases $(80 \%)$ both per operatively and on computed tomography. The extent of the disease was almost comparable per operatively and on computed tomography. Tegmen tympani erosion was seen in 28 cases $(31.11 \%)$ per operatively but only in 17 cases $(18.88 \%)$ on computed tomography. Similarly sinus plate erosion was observed in 8 cases $(8.88 \%)$ per operatively and 6 cases $(6.66 \%)$ on computed tomography. Facial N. dehiscence was seen in 29 cases $(32.22 \%)$ per operatively whereas on computed tomography, it was observed in 13 cases $(13.33 \%)$. Lateral semi-circular canal fistula was seen in 14 cases $(15.55 \%)$ per operatively and in 12 cases $(13.33 \%)$ on computed tomography. Per operatively Malleus erosion was observed in 32 cases $(35.55 \%)$ and in 10 cases $(33.33 \%)$ on computed tomography. Similarly, incus erosion was seen in 69 cases $(76.66 \%)$ preoperatively and in 43 cases $(47.77 \%)$ on computed tomography. Stapes was found eroded in 36 cases $(40 \%)$ per operatively and in 17 cases $(18.88 \%)$ on computed tomography. Preoperatively disease outside middle ear was seen in 17 cases $(18.88 \%)$ whereas on computed tomography it was observed in 16 cases $(17.77 \%)$.

Table 2: Surgery performed among study subjects

\begin{tabular}{|l|l|l|}
\hline Surgery done & No. of cases & Percentage \\
\hline Modified Radical mastoidectomy & 13 & $13.33 \%$ \\
\hline $\begin{array}{l}\text { Modified Radical Mastoidectomy } \\
\text { with Tympanoplasty }\end{array}$ & 38 & $42.22 \%$ \\
\hline Intact Canal Wall Mastoidectomy & 4 & $4.44 \%$ \\
\hline $\begin{array}{l}\text { Intact Canal Wall Mastoidectomy } \\
\text { with Tympanoplasty }\end{array}$ & 14 & $15.55 \%$ \\
\hline Cortical Mastoidectomy & 2 & $2.22 \%$ \\
\hline $\begin{array}{l}\text { Abscess drainage followed by } \\
\text { Modified Radical mastoidectomy }\end{array}$ & 10 & $11.11 \%$ \\
\hline $\begin{array}{l}\text { Abscess drainage followed by } \\
\text { Cortical Mastoidectomy }\end{array}$ & 5 & $5.55 \%$ \\
\hline $\begin{array}{l}\text { Atticotomy with type 1 } \\
\text { Tympanoplasty }\end{array}$ & 4 & $4.44 \%$ \\
\hline
\end{tabular}

All the patients included in present study had undergone mastoid exploration. 13 cases (14.44\%) underwent Modified Radical Mastoidectomy while in 38 patients (42.22\%) Modified Radical Mastoidectomy with Tympanoplasty was performed. 4 patients (4.44) was subjected to Intact Canal Wall Mastoidectomy and in 14 patients (15.55\%) Intact Canal Wall Mastoidectomy with Tympanoplasty was done. 2 patients $(2.22 \%)$ underwent Cortical Mastoidectomy while in 10 patient (11.11\%) Atticotomy with type 1 Tympanoplasty was done as no significant disease was found in computed tomography as well as per operatively. In patients who had complications in form of brain abscess as diagnosed on computed tomography, 10 patients (11.11\%) had undergone Abscess drainage followed by Modified Radical Mastoidectomy and in 4 patients (4.44\%) Abscess drainage followed by Cortical Mastoidectomy was done.

\section{Discussion}

CSOM is an important health problem in children and adults world-wide, but more so in developing countries. It can cause chronic hearing loss which has a negative impact on the development of speech, language and social interaction as well as school and workplace performance and is responsible for significant morbidity and mortality due to complications. According to a report by WHO, India belongs to the highest ( $>4 \%$ ) CSOM prevalent countries. Topical antibiotics are the mainstay of therapy while systemic antibiotics are given in acute exacerbations and in complications due to CSOM. ${ }^{[2]}$

The present study was conducted to evaluate the role of preoperative computed tomography in assessing patients of unsafe chronic supportive otitis media and correlating it with preoperative findings so that attempts can be made to restore or conserve hearing and promote healing, after the excision of disease from the middle ear and mastoid. A total of 90 cases were selected and each of the selected cases of 


\section{Shukla et al; Preaperative Computed Tamagraphy in Unsale Chronic Supppurative Otitis Media}

unsafe chronic suppurative otitis media were subjected to computed tomography of temporal bone. In every patient both axial and coronal sections were taken, taking high resolution section of $1-2 \mathrm{~mm}$ thickness. These cases were undertaken for surgical exploration and finally an attempt was made to correlate the preoperative findings with preoperative computed tomography findings.

In past studies computed tomography was found up to $100 \%$ sensitive in detecting a soft tissue mass preoperative. $^{[6-9]}$ Our data showed a slightly lower sensitivity of $91.95 \%$. This discrepancy could be because of greater sample size in our study. However the specificity and Positive predictive value in this regard were both $100 \%$. However, we could not distinguish cholesteatoma from other soft tissue disease, and this again was the experience of most authors. The differential diagnosis of soft tissue mass is often quite difficult with computed tomography. We have been unsuccessful most of the times in differentiating pathologic processes on the basis of computed tomography number. Acquired cholesteatoma, granulation tissue (in the absence of hemorrhage) and middle ear effusion all share computed tomography numbers ranging from 40 to 65 . We therefore must rely on secondary findings to help in differential diagnosis. Fluid can often be differentiated form cholesteatoma formation on the basis of dependency (provided two projection are used), and because it seems to be restricted between tendinous and ligamentous boundaries. Cholesteatoma on the other hand, have a propensity for ossicular destruction and will not gravitate. Thus after clinical examination, otoscopy and diagnosis of cholesteatoma, computed tomography can determine its extent by revealing the combination of a soft tissue mass and bone erosion with $80 \%$ specificity. ${ }^{[10,11]}$ Although cholesteatoma is said to show a lower attenuation than granulation tissue, the difference is subtle and only Magnetic Resonance Imaging can differentiate between the two.

In studies on efficiency of computed tomography in defining the extent of disease preoperatively, O'Donoghue et al and MacAfee et al independently found computed tomography to be highly accurate. ${ }^{[12,13]}$ O'Reilly et al, in his study, corroborated the above studies with a 100\% sensitivity of computed tomography in defining the extent of disease. ${ }^{[14]}$ In our study, the sensitivity and Positive Predictive Value were both $97.5 \%$ which is in agreement with the aforementioned studies.

O' Donoghue et al, reported a sensitivity of $50 \%$ in identifying Tegmen tympani erosion but did not report his false positives. ${ }^{[12]} \mathrm{O}$ ' Reilly et al showed sensitivity of $46 \%$ and specifity of $84 \% .{ }^{[14]}$ Jeckler et al, reported a sensitivity of $100 \%$ but a PPV of $33.33 \%$ in this regard. ${ }^{[15]}$ Macfee et al, ${ }^{[13]}$ showed a sensitivity of $50 \%$ and a positive predictive value of $100 \%$ for detecting tegmen erosion. In our study, the sensitivity and positive predictive value were both $60.71 \%$. These non-correlating values can be explained partly by the very small number of patients with tegmen erosion in these studies, and also on the fact stated by O'Reilly et al. ${ }^{[14]} \mathrm{He}$ commented that it is not possible to demonstrate reliably a dehiscence in the tegmen on axial scan alone but even using coronal cuts they found that the effect of partial volume averaging with adjacent soft tissue could give a false impression of tegmen erosion.

In detecting sinus plate erosion on computed tomography our study showed sensitivity of $75 \%$, specificity of $96 \%$, positive Predictive Value of $75 \%$ and negative Predictive Value of $97.53 \% 16$. Hence in our study, we demonstrated that, in pinpointing patients with sinus plate erosion in unsafe chronic suppurative otitis media, computed tomography was highly effective. However, it's utility in spotting out those with a normal sinus plate was limited.

In previous studies, the sensitivity of computed tomography in detecting facial canal dehiscence varied widely with values of $0 \% 6,25 \% 7,44 \% 8$, and $100 \% 9$. The specificity has been reported only by O'Reilly as $85 \% 14$. In our study, the sensitivity was $44.82 \%$ and specificity was $96.72 \%$, which was comparable to the O.' Reilly study. ${ }^{[14]}$ These non-compliant results can be explained on the fact that the visualization on thin bony structures like facial nerve canal may be misleading due to errors in scanning eroded portions due to the fact that the computer averages their density with adjacent soft tissue and air.

The labyrinthine fistula continues to be one of the most common complications of chronic suppurative otitis media. Its frequency varies approximately from $4 \%$ to $12 \%$. In nearly $90 \%$ of patients the labyrinthine fistula is located in lateral semicircular canal. An extensive clinical examination supported by imaging studies is essential for the preoperative diagnosis of lateral semicircular canal fistula. O'Reilly et al stated that axial scans are more satisfactory as they depict lateral semicircular canal in it entirely and are less likely to produce false positives. Nevertheless useful information can also be obtained from coronal scans and hence both sections should be employed. In previous studies, the sensitivity of computed tomography in detecting lateral semicircular canal fistula was approximately $55 \% 14$. In one study, however, Rai et al, ${ }^{[17]}$ showed a sensitivity of $97 \%$ for the same. The result of our study showed a sensitivity of $85.71 \%$ which was comparable. The specificity, Positive Predictive Value and Negative Predictive Value for our data in this regard was $97.14 \%$, $60 \%$ and $97.14 \%$ respectively. In conclusion, sensitivity of computed tomography in diagnosing lateral semicircular canal fistulas was moderate.

It is relatively easy to visualize the bodies of the malleus and the incus on computed tomography but this has little clinical value unless the whole ossicular chain can be demonstrated. $^{[18]}$ The long processes of the malleus and incus, and the stapes superstructure are the components most at risk in chronic suppurative otitis media but are also the most difficult to demonstrate on computed tomography MacAfee et $\mathrm{al}^{[13]}$ were able to demonstrate the state of ossicular chain in $89 \%$ of the cases scanned. On the other hand, Jackler et $\mathrm{al},{ }^{[16]}$ were able to predict the state of ossicular chain in only $7 \%$ of their cases. Phleps and Wright, ${ }^{[19]}$ doubted that computed tomography could demonstrate the ossicular chain reliably because of partial volume averaging and tissue silhouetting. The malleus was the ossicle whose presence was predicted with the greatest accuracy with the sensitivity of $100 \%$ of detection on computed tomography. ${ }^{[17]}$ 


\section{Shukla et al; Preaperative Computed Tamagraphy in Unsale Chranic Supppurative Otitis Media}

In our study, the sensitivity was $94.11 \%$ and specificity was $92.85 \%$ and Positive Predictive Value of $88.88 \%$. O'Donoghue et $\mathrm{al}^{[6]}{ }^{[6]}$ reported a sensitivity of $81.4 \%$ in identifying incus erosion whereas in our study its sensitivity was $62.31 \%$. He also reported sensitivity of $85.71 \%$ and specificity of $23.25 \%$ in detecting absences of stapes supprastructure. However in our study, its sensitivity was $47.22 \%$ and specificity was $37.03 \%$. In our study we were not satisfactorily able to detect ossicular chain integrity or disruption due to failure in identifying long process of incus and/or the stapes supprastructure.

On comparing our results with previous studies in literature we found that computed tomography proved to be a necessary tool for planning surgery in every case where disease spreads outside middle ear cleft. In a study conducted by Payal +20 , computed tomography showed sensitivity of $97 \%$ and a positive Predictive Value of $94 \%$ in diagnosis of disease outside middle ear cleft. In our study, the sensitivity was $94.11 \%$, specificity was $100 \%$ and Positive Predictive Value of $100 \%$. The sensitivity in our study was almost comparable with previous studies.

Computed tomography is subjected to certain artifacts produced by computer generation of the image. One of those is called volume averaging which at times produces as apparent dehiscence in thin bony structures. This artifact results from a computer averaging of the density of thin bone plate with that of adjacent soft tissue within the same high resolution slice. For the above stated reason, computed tomography scans occasionally give a misleading impression of bone erosion including lateral semicircular canal, tegmen tympani, sinus plate and facial canal. Jackler et al, ${ }^{[16]}$ stated that most of these pitfalls can be avoided by employing more than one section, bilateral comparison and correct interpretation of the scans. Another drawback of computed tomography is its inability to distinguish definitively between cholesteatoma and granulation tissue or other pathologic tissue with similar radiographic density. ${ }^{[21]}$ Lastly the cost factor for computed tomography should also be kept in mind as it is an expensive modality.

\section{Conclusion}

The present study was conducted to evaluate the role of preoperative computed tomography in assessing patients of unsafe chronic suppurative otitis media and correlating it with preoperative findings so that we know beforehand, the expected pathology with a reasonable surety, so that attempts can be made to restore or conserve hearing and promote healing, after the excision of disease from the middle ear and mastoid. A total of 90 cases were selected and each of the selected cases of unsafe chronic suppurative otitis media were examined clinically and subjected to computed tomography of temporal bone. In every patient both axial and coronal sections were taken, taking high resolution section of 1-2 mm thickness. These cases were undertaken for surgical exploration and finally an attempt was made to correlate the preoperative findings with preoperative computed tomography findings.

In conclusion, the present study pointed that high resolution computed tomography scanning is a modality which can accurately image the pathological anatomy in unsafe chronic suppurative otitis media and represents a major advance in the diagnostic imaging of this disease. Its use by otologists is encouraged, especially in patients who have or are suspected of having complex problems and in whom the maximum information is desirable for preoperative assessment.

\section{References}

1. Jose Acuin, Philippines. Chronic suppurative otitis media Burden of Illness and Management Options. Child and Adolescent Health and Development Prevention of Blindness and Deafness. World Health Organization (WHO), Geneva, Switzerland, 2004.

2. Khatoon A, Rizvi M, Sultan A, Khan F, Sharma M, Shukla I, Khan HM. Chronic suppurative otitis media: a clinico-microbiological menace. Int J Res Med Sci 2015;3(8):1932-6.

3. WHO. Chronic suppurative otitis media. Burden of illness and management

options

2004.http://www.who.int/childadolescenthealth/New_Publications/CH ILD_HEALTH/ISBN_92_4_159158_7.pdf.

4. Leighton SEJ, Robson $\overline{A K}$, Anslow $\mathrm{P}$, Milford CA. The role of CT imaging in the management of chronic suppurative otitis media. Clin Otolaryngol. 1993;18:23-29.

5. Singh. A, Pandey. S and Gaur. A. 2018. "Burden of noncommunicable diseases on two different division of Uttarakhand: Adult health indicator", International Journal of Development Research, 8, (12), 24480-24485.

6. Niveditha J, Chidananda R. Clinical study of correlation between preoperative findings of HRCT with intra-operative findings of cholesteatoma in cases of CSOM. Indian J Anatomy Surgery Head, Neck Brain 2017;3(1):1-5.

7. Kangsan J, Fooanant S, Ruckpharpunt K, Nanachareon N, Teoflakul S Extracranial and intracranial complications of suppurative otitis media. Report of 102 cases. J. Laryngol. Otol. 1993;107:99-1004.

8. Singh B, Maharaj TJ. Radical mastoidectomy: its place in otitic intracranial complications. J. Laryngol. Otol. 1993;107:1113-8.

. Campbell JP, Pllsbury HC. The use of computerized tomoraphic imaging in revision mastoid surgery of chronic otitis media. American J. of Otology 1990;11:387-394

10. Freng A, Larsen PL, Nordhus T. Cholesteatoma of the temporal bone. Preoperative CT versus Peroperative findings. Scandinavian Audiology Supplement. 1988;30:185-188.

11. Aminifarshidmehr N. (1996). The management of chronic suppurative otitis media with acid media solution Am J Otol 17 24-25.

12. O'Donoghue G M, Bates G J. Anslow P. Rothera P. The predictive value of high resolution computerized tomography in chronic suppurative ear disease. Clinical otolaryngology 1983;12:89-96.

13. Mafee M F, Levin BC, Apple Baum E Cancer, Compos M, James Cancer F. Cholestaetmoa of middle ear and mastoid: A comparison of the CT scan and operative findings. Otolaryngology Clinics of North America 1988;21:265-293.

14. O'Reilly BJ, Chavertton Ear B, Wylie.1, Thakkar C, Butler P, Sathanathan N, Morrison GA, Kenyon GS. Value of computed tomography scanning in chronic suppurative otitis media; $\mathrm{J}$ of Laryngology and Otology Dec 1991;105:990-994.

15. Jackler RK, Dillon WP, Schindler RA. Computed tomography in suppurative ear disease: a correlation of surgical and radiographic findings. Laryngoscope. 1984;94:746-752.

16. Shaffer KA, Haughton VM, Wilson CR. High resolution computed tomography of the temporal bone. Radiology. 1980;134:409-414.

17. Rai T. Radiological study of the temporal bone in chronic otitis media: Prospective study of 50 cases. Indian J Otol. 2014;20(2):50.

18. Pandey $\mathrm{S}$, Singh $\Lambda$, Gaur $\Lambda$. Polynomial approach modeling among diabetic patients associated with age in rural hilly population of Dehradun district, Uttarakhand. Int J Res Med Sci 2018;6:1-5.

19. Phelps P D, Wright A.. Imaging cholesteatoma. Clinical Radiology 1940;41:156-162.

20. Payal, G., Pranjal, K., Gul, M., Mittal, M. K., \& Rai, A. K. (2012) Computed tomography in chronic suppurative otitis media: value in 
India,64(3), 225-229. doi:10.1007/s12070-011-0325-4.

21. Kvestad E, Kvaerner KJ, Mair IWS. Acute Mastoiditis: predictors for

Copyright: (C) the author(s), publisher. Asian Journal of Medical Radiological Research is an Official Publication of "Society for Health Care \& Research Development". It is an open-access article distributed under the terms of the Creative Commons Attribution Non-Commercial License, which permits unrestricted non-commercial use, distribution, and reproduction in any medium, provided the original work is properly cited.

How to cite this article: Shukla N, Sharma V, Giri RK. Correlation and Evaluation of the Preoperative Computed Tomography with Preoperative Surgical Findings in Patients with Unsafe Chronic Supppurative Otitis Media. Asian J. Med. Radiol. Res. 2019;7(1):42-46.

DOI: dx.doi.org/10.21276/ajmrr.2019.7.1.10

Source of Support: Nil, Conflict of Interest: None declared. 